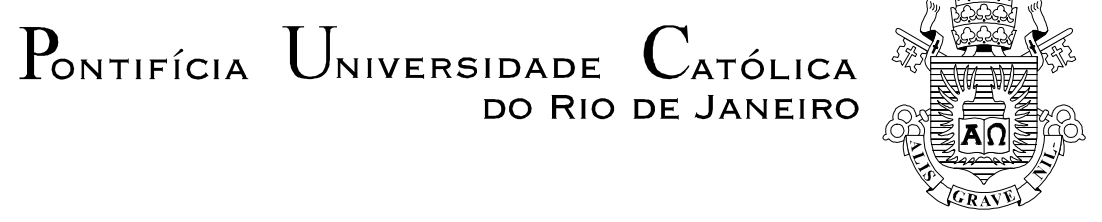

Gustavo Antunes Sengès

\title{
- FENÔMENO DA CORREÇÃO LEGISLATIVA DE DECISÃO JUDICIAL
}

\section{Dissertação de Mestrado}

Dissertação apresentada como requisito parcial para obtenção de grau de Mestre pelo Programa de Pós-Graduação em Direito do Departamento de Direito da PUC-Rio.

Orientadora: Gisele Guimarães Cittadino

Rio de Janeiro

Maio de 2010 


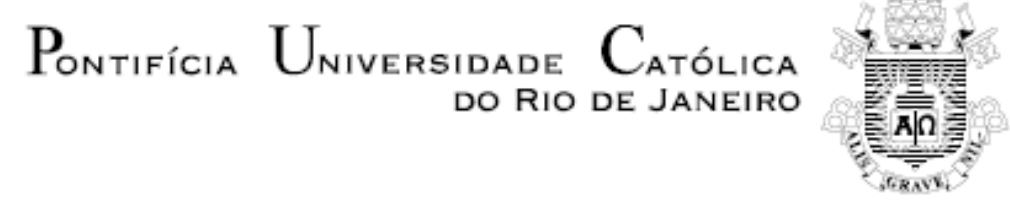

Gustavo Antunes Sengès

\section{- FENÔMENO DA CORREÇÃo LEGISLATIVA DE DECISÃO JUDICIAL}

Dissertação apresentada como requisito parcial para obtenção do título de Mestre pelo Programa de Pós-graduação em Direito do Departamento de Direito da PUC-Rio. Aprovada pela Comissão Examinadora abaixo assinada.

Profạ. Ana Lúcia de Lyra Tavares

Orientadora

Departamento de Direito - PUC-Rio

Prof. José Ribas Vieira

Departamento de Direito - PUC-Rio

Prof. Daniel Antonio de Moraes Sarmento

UERJ

Profa. Mônica Herz

Vice-Decano de Pós-Graduação do Centro de

Ciências Sociais - PUC-Rio

Rio de Janeiro, 28 de maio de 2010. 
Todos os direitos reservados. É proibida a reprodução total ou parcial do trabalho sem autorização da Universidade, do autor e do orientador.

\section{Gustavo Antunes Sengès}

Graduou-se em Bacharel em Direito no ano de 2006 pela Universidade Cândido Mendes (UCAM). Especialista em Análise Internacional pela Universidade Federal do Rio de Janeiro (UFRJ).

Ficha Catalográfica

\section{Sengès, Gustavo Antunes}

O Fenômeno Da Correção Legislativa De Decisão Judicial / Gustavo Antunes Sengès ; orientadora: Ana Lúcia de Lyra Tavares - 2010.

$$
134 \text { f. ; } 30 \mathrm{~cm}
$$

Dissertação (Mestrado em Direito)-Pontifícia Universidade Católica do Rio de Janeiro, Rio de Janeiro, 2009.

Inclui bibliografia

1. Direito - Teses. 2. Poder Judiciário. 3. Poder Legislativo. 4. jurisdição constitucional. 5. relação interpoderes. 6. correção legislativa. 7. decisão judicial. I. Tavares, Ana Lúcia de Lyra . II. Pontifícia Universidade Católica do Rio de Janeiro. Departamento de Direito. III. Título.

CDD: 340 
A

Meu pai, com quem convivi até nove anos de idade. Dele, herdo a retidão de caráter, a valorização do conhecimento e as doces memórias de uma infância que o tempo nunca conseguirá apagar. Guardo, em silêncio, a esperança de que um dia nos reencontraremos.

A

Minha mãe, exemplo de mulher forte e de amor incondicional. Sem seu incentivo - em todos os sentidos- esta realização não teria sido possível. Obrigado por tudo.

A

Paula, minha mulher, pela paciência e companheirismo, mesmo nos momentos difíceis (e foram muitos). O espaço é curto para expressar todo o meu amor e minha gratidão. 


\section{Agradecimentos}

A minha orientadora, Professora Ana Lucia de Lyra Tavares, agradeço a gentileza, a paciência e, acima de tudo, sua serena sabedoria compartilhada ao longo de um agradável convívio. Sem sua cuidadosa orientação esta dissertação não teria chegado ao fim.

Ao Professor José Ribas Vieira, pela imensa disponibilidade dedicada a todos os seus alunos. Sua incessante busca pelo saber e enorme generosidade intelectual, seguramente, pautarão minha vida acadêmica e pessoal.

Ao professor Carlos Alberto Plastino. Com ele aprendemos que não devemos almejar o aprimoramento intelectual para sermos melhores que o outro, mas para sermos melhores com o outro.

Ao ex-coordenador e professor Adrian Sgarbi, pela gentil acolhida e maneira democrática como atendia às nossas demandas discentes. Igualmente, agradeço à atual coordenadora, a Professora Gisele Cittadino por manter aberta essa via de comunicação, bem como pelas suas preciosas lições.

Aos professores Rubén Martínez Dalmau e Robert Miller. Agradeço a ambos, pela grata oportunidade de poder desfrutar um pouco da riqueza dos sistemas jurídicos estrangeiros.

A todos os professores do Departamento de Direito da PUC-Rio. Cada um, ao se modo, compõe esse precioso mosaico de distintos conhecimentos e perspectivas, do qual orgulhosamente pude fazer parte.

Gostaria de agradecer, ainda, ao Anderson e à Carmen. Sem eles nossa caminhada teria sido bem mais desgastante.

Por fim, um carinhoso agradecimento aos meus colegas, com quem tive o prazer de dividir inesquecíveis momentos, em especial a Alceu Maurício Júnior, Mônica de Ré, Alexandre Demidoff, Natasha Vianna e Janaína Matida.

Ao CNPq e à PUC, que tornaram tudo isso possível. 


\section{Resumo}

Sengès, Gustavo Antunes; Tavares, Ana Lúcia de Lyra. O Fenômeno Da Correção Legislativa De Decisão Judicial . Rio de Janeiro, 2010, 134p. Dissertação de Mestrado - Departamento de Direito, Pontifícia Universidade Católica do Rio de Janeiro.

O debate em torno da legitimidade da jurisdição constitucional em detrimento da vontade majoritária, que o Legislativo representa, tem sido objeto de estudo no direito nacional e estrangeiro. No Brasil, a expansão da jurisdição constitucional preocupa estudiosos do tema que vêem no protagonismo do Supremo Tribunal Federal riscos ao processo democrático. Neste cenário, a busca pela efetividade da Constituição, a "judicialização" dos direitos e as novas ameaças enfrentadas pelas sociedades contemporâneas, conferem ao Judiciário um papel ainda mais proeminente. Através do estudo de casos e da análise de alguns ordenamentos estrangeiros, a presente dissertação examina o fenômeno da correção legislativa de decisão judicial, como um meio capaz de equilibrar a sensível relação entre esses dois Poderes e restabelecer a harmonia do processo decisório constitucional.

\section{Palavras-chave}

Poder Judiciário, Poder Legislativo, jurisdição constitucional, relação interpoderes, correção legislativa e decisão judicial. 


\section{Abstract}

Sengès, Gustavo Antunes; Tavares, Ana Lúcia de Lyra(Advisor): The Practice Of Legislative Override Of Judicial Decision. Rio de Janeiro. 2010. 134p. Dissertação de Mestrado. Departamento de Direito. Pontifícia Universidade Católica do Rio de Janeiro.

The debate about the legitimacy of judicial review to frustrate the majority's will as expressed by a democratically elected legislature has been the object of study and criticism in both national and foreign Law. In Brazil, some scholars argue that the expansion of the Supreme Court's judicial review power may undermind the democratic process itself. In this scenario, the search for effectiveness of the Constitution, the "judicialization" of rights and the new threats faced by contemporary societies, give the Judiciary a more prominent role. Through case studies and an analysis of foreign legal systems, this thesis examines the overrides of Supreme Court decisions by Legislature as a mean through which the equilibrium between the Judicial and Legislative branches are rebalanced and harmonized within the constitutional decision-making process.

\section{Key words}

Judicial Branch, Legislative Branch, judicial review, interbranch relationship, legislative overrides and judicial decisions. 


\section{SUMÁRIO}

$\begin{array}{ll}1 \text { INTRODUÇÃO } & 10\end{array}$

2 Jurisdição constitucional: novas perspectivas 19

2.1 O caso dos exploradores de caverna: uma releitura 19

2.2 Teorias sobre o modelo de jurisdição constitucional 25

2.3 A jurisdição constitucional no Brasil 31

2.3.1 Expansão 31

2.3.2 Adequação à realidade jurídica e política 40

3 Alternativas à jurisdição constitucional e a correção legislativa de decisão judicial

3.1. O modelo canadense de controle de constitucionalidade.

A cláusula "notwithstanding” e a teoria do diálogo Institucional 51

3.2. A proposta apresentada pelo denominado "Novo

Constitucionalismo Latino-Americano": a desconfiança em relação

ao constituinte derivado e todo poder ao povo 63

3.3. O direito americano: confronto interpoderes ou diálogo político? 73

3.4. O "fenômeno" da correção legislativa de decisão judicial

no direito brasileiro $\quad 84$

4 Análise de casos de correção legislativa de decisão judicial no Brasil 100

4.1 O caso paradigma: a contribuição de custeio para iluminação pública 100

4.2. Criação, fusão, incorporação e desmembramento de municípios 104

4.3. Recomposição das Câmaras Municipais 106

4.4 A correção por proposta de emenda constitucional. A PEC 386:

exigência de diploma de jornalismo 109

5 CONCLUSÃO 116

6 BIBLIOGRAFIA $\quad 120$ 
Navegadores antigos tinham uma frase gloriosa:

"Navegar é preciso; viver não é preciso".

Quero para mim o espírito [d]esta frase, transformada a forma para a casar como eu sou:

Viver não é necessário; o que é necessário é criar. Não conto gozar a minha vida; nem em gozá-la penso.

Só quero torná-la grande, ainda que para isso tenha de ser o meu corpo e a (minha alma) a lenha desse fogo.

Só quero torná-la de toda a humanidade; ainda que para isso tenha de a perder como minha.

Cada vez mais assim penso. Cada vez mais ponho da essência anímica do meu sangue o propósito impessoal de engrandecer a pátria e contribuir para a evolução da humanidade.

É a forma que em mim tomou o misticismo da nossa Raça. 